\title{
La edición de revistas académicas de extensión universitaria
}

Cecilia lucci y Lucas Cardozo

Equipo editorial de la Revista de Extensión

Universitaria + E. Universidad Nacional

del Litoral, Argentina.

revistaextensionun/@gmail.com

\section{La importancia de las revistas académicas en el campo de la extensión}

Sin lugar a dudas, uno de los puntos más importantes de las agendas universitarias latinoamericanas en materia de extensión universitaria es el reconocimiento de su valor académico y formativo.

Los modos en las que las instituciones de educación superior se interrogan, investigan e intervienen -o no- sobre problemáticas sociales, definen no solo modelos de extensión sino modelos de universidad. En el centro de estos modelos se juega el concepto mismo del conocimiento, el tipo de formación y de profesionales que promueve y el papel que se le adjudica a la universidad como institución social.

En estas definiciones, las revistas académicas de extensión vienen cumpliendo un rol fundamental no solo como divulgadoras de las acciones y políticas que se vienen desarrollando en distintos países de América Latina y el Caribe, sino como espacios en donde se pone de relieve la densidad conceptual, teórica y metodológica, vinculada a un campo discursivo heterogéneo, conflictivo y complejo.

Esta novedad en las discusiones se tradujo al campo editorial. De allí que sean escasas las revistas académicas de extensión y que tengan una historia muy breve: con excepción de la revista Em Extensão (que cumplió su 20 aniversario), el resto es posterior a 2010.

La reciente inclusión de algunas revistas de extensión en índices científicos internacionales; la aparición de nuevos formatos digitales; la presión por la utilización de determinados softwares; la suscripción a políticas de acceso abierto; la sustentabilidad de las publicaciones; la formación en gestión editorial; la tensión entre las políticas del leguaje y la escritura académica, son algunos de los dilemas que traccionan a las revistas de extensión.

Para discutir estas cuestiones, la revista +E organizó un encuentro de equipos editoriales de revistas de extensión en el marco del III Congreso de Extensión Universitaria de AUGM "Democracia, derechos humanos e inclusión social, camino a los 100 años de la Reforma Universitaria", realizado en la Universidad Nacional del Litoral (Santa Fe, Argentina), del 6 al 9 de septiembre de 2017.

\section{Encuentro de Editores de Revistas de Extensión}

La convocatoria se efectuó a 41 revistas de extensión relevadas por el equipo editorial de +E, pertenecientes tanto a facultades como a áreas del rectorado de universidades de América Latina y el Caribe. ${ }^{1}$

1) Para ampliar información, ver: lucci, C. y Cardozo, L. (2018). Revistas académicas de extensión universitaria: aportes e interpelación a la gestión universitaria. El caso de +E. Recuperado de extension.unicen.edu.ar/jem/subir/ uploads/2018_378.docx (29/05/2018). 
El Encuentro se planteó con tres objetivos: (i) visibilizar la diversidad de publicaciones periódicas universitarias existentes en extensión universitaria; (ii) promover un ámbito de discusión sobre las problemáticas comunes de la edición universitaria, y (iii) generar un espacio para construir estrategias compartidas de trabajo de revistas dedicadas a la temática de extensión.

Con estos propósitos, se reunieron 13 equipos editoriales procedentes de Argentina, Brasil, Costa Rica y Uruguay (ver Tabla 1).

Tabla 1. Equipos editoriales de revistas de extensión, institución de pertenencia y país de origen asistentes al I Encuentro de Editores, 2017.

\begin{tabular}{|c|c|c|}
\hline Revista & Institución & País \\
\hline Cuadernos de Extensión de la UNLPam & $\begin{array}{l}\text { Universidad Nacional de La Pampa. Secretaría } \\
\text { de Cultura y Extensión Universitaria. }\end{array}$ & Argentina \\
\hline EXT & $\begin{array}{l}\text { Universidad Nacional de Córdoba } \\
\text { Secretaría de Extensión. }\end{array}$ & Argentina \\
\hline Masquedós. Revista de Extensión Universitaria. & $\begin{array}{l}\text { Universidad Nacional del Centro de la Provincia } \\
\text { de Buenos Aires. Secretaría de Extensión. }\end{array}$ & Argentina \\
\hline $\begin{array}{l}\text { Extensionismo, Innovación y Transferencia } \\
\text { Tecnológica: Claves para el Desarrollo }\end{array}$ & $\begin{array}{l}\text { Universidad Nacional del Nordeste. Facultad de } \\
\text { Ciencias Exactas y Naturales y Agrimensura. }\end{array}$ & Argentina \\
\hline Tekohá & $\begin{array}{l}\text { Universidad Nacional de Misiones. Secretaría } \\
\text { de Extensión y Vinculación Tecnológica de la } \\
\text { Facultad de Humanidades y Ciencias Sociales. }\end{array}$ & Argentina \\
\hline Revista de Extensión Universitaria $+E$ & Universidad Nacional del Litoral. & Argentina \\
\hline Em Extensão & $\begin{array}{l}\text { Universidade Federal de Uberlândia. } \\
\text { Pró-Reitoria de Extensão e Cultura. }\end{array}$ & Brasil \\
\hline Elo: Diálogos em Extensão & $\begin{array}{l}\text { Universidade Federal de Viçosa. } \\
\text { Pró-Reitoria de Extensão e Cultura. }\end{array}$ & Brasil \\
\hline Revista de Extensão Guará & $\begin{array}{l}\text { Universidade Federal do Espírito Santo. } \\
\text { Pró-Reitoria de Extensão. }\end{array}$ & Brasil \\
\hline Revista da Extensão & $\begin{array}{l}\text { Universidade Federal do Rio Grande do Sul. } \\
\text { Pró-Reitoria de Extensão. }\end{array}$ & Brasil \\
\hline Revista Ciência Em Extensão & $\begin{array}{l}\text { Universidade Estadual Paulista “Julio De } \\
\text { MesquitaFilho" (UNESP). }\end{array}$ & Brasil \\
\hline Revista de Extensión: Universidad en Diálogo & $\begin{array}{l}\text { Universidad Nacional de Costa Rica. } \\
\text { Vicerrectoría de Extensión. }\end{array}$ & Costa Rica \\
\hline "it" Salud Comunitaria y Sociedad & $\begin{array}{l}\text { Universidad de la República. Programa } \\
\text { Aprendizaje en Extensión (APEX). }\end{array}$ & Uruguay \\
\hline
\end{tabular}

Fuente: elaboración propia. 
En la primera parte de la reunión se realizó una presentación de los equipos editoriales donde los participantes expusieron una breve semblanza de sus tareas y donde se manifestó, en términos generales, la importancia de un sector editorial emergente en términos teóricos, metodológicos y prácticos del quehacer extensionista.

La segunda parte continuó con el debate sobre los desafíos que enfrentan las publicaciones periódicas, centrándose puntualmente en:

- Las capacidades, perfiles y tareas que hacen a la gestión editorial.

- El proceso editorial (comunicación y difusión; convocatorias; revisores; escritura; corrección de estilo; traducciones; diseño).

- La indexación: problemas y la necesidad de capacitaciones sobre la temática.

- Nuevos formatos editoriales: presentación a cargo de Agustín Longoni (Área de Telematica de la Universidad Nacional del Litoral) sobre las diferentes opciones de los formatos electrónicos de publicación.

Por último, en la tercera parte, a modo de conclusión, los participantes pusieron en valor esta primera instancia de trabajo y propusieron dar continuidad a este espacio en otra universidad. Asimismo, se planteó en la elaboración de una base de datos actualizada con todas las revistas periódicas, así como una base común de revisores con sus perfiles académicos para que puedan ser utilizados en las instancias de referato de todas las revistas de acuerdo con las diferentes áreas que abarca la extensión universitaria.

Es así que en 2019 se realizará el II Encuentro de Editores de Revistas de Extensión en Chile, en el marco del IV Congreso de AUGM. Los equipos editoriales se encuentran trabajando en el temario y en las dinámicas que implicará este encuentro. 